\title{
Neue Behandlungsform für periodontale Taschen Sicher und effektiv den subgingivalen Biofilm entfernen
}

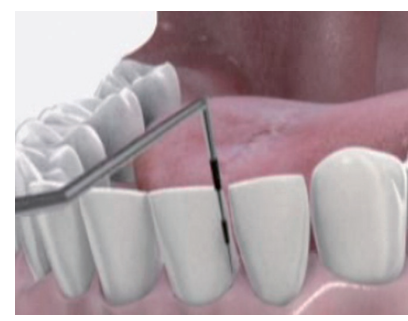

Abb. 1 Zu Beginn stellt man alle periodontalen Taschen tiefer als 5 mm fest.

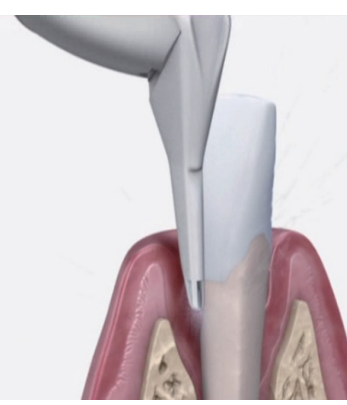

Abb. 5 Mit lediglich geringem Druck gibt die Düse das Luft-, Pulver-, Wassergemisch aus und entfernt trotzdem den kompletten Biofilm.

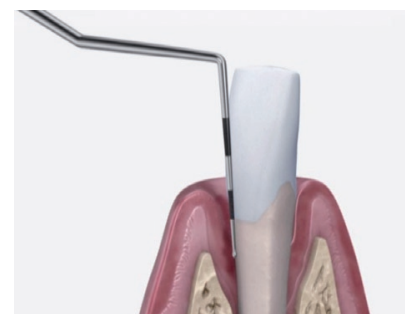

Abb. 2 Den infizierten Bereich im Anschluss vorab erweitern (Scaling), z. B. mit dem EMS Piezon Ultraschall Scaler.

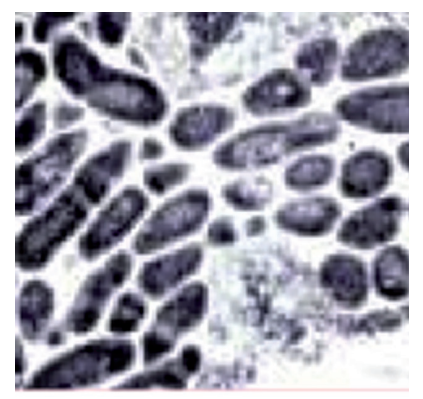

Abb. 6 Der Biofilm - unterschätztes Übel: Mehr als 15000 Bakterienstämme werden durch ihn gegen Pharmazeutika geschützt.

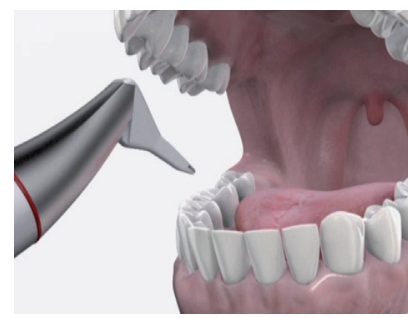

Abb. 3 Die Perio-Düse direkt in die zu behandelnde Region geben.

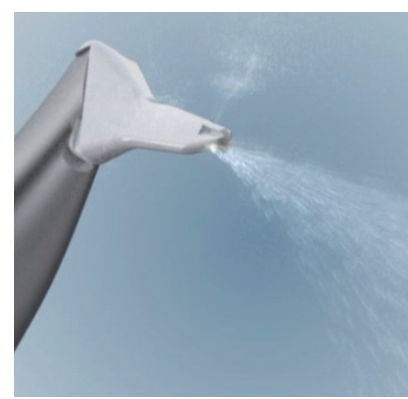

Abb. 7 Im Ergebnis eine effiziente, sanfte Behandlung mit wirksamen Perio-Polishing und sanfter Massage des Zahnfleisches.

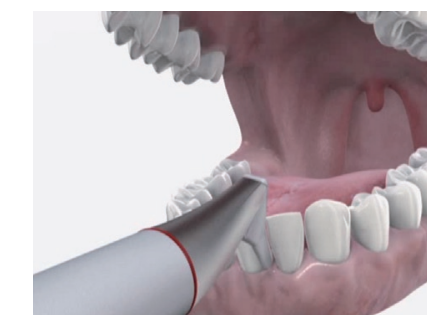

Abb. 4 Jede Tasche 5 s behandeln, indem man schnelle Vor- und Rückwärtsbewegungen macht.

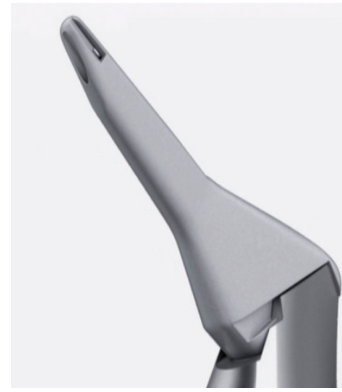

Abb. 8 Die Perio-Düse hat 3 Öffnungen: 2 für die LuftPulvermischung und 1 für die Wasserzufuhr. Die Düse ist biokompatibel und nur für den einmaligen Gebrauch geeignet.
Periodontale Erkrankungen, inklusive Gingivitis und Parodontitis, gehören zu bekanntlich ernsthaften Infektionen, die - wenn man sie unbehandelt lässt - zum Zahnverlust führen können. Die Hauptursache dafür ist bakterielle Plaque, auch als Biofilm bekannt: ein klebriger Belag, der sich hartnäckig auf den Zähnen bildet. Über 15000 Bakterienstämme siedeln sich in ihm an und können sich ungehindert ausbreiten. Der Biofilm schützt die Bakterien gegen Pharmazeutika. So ist die Immunabwehr des Körpers unter Umständen machtlos. Um das Eindringen der Keime zu verhindern, löst der Körper „in Notwehr“ einen Knochenabbauprozess aus.

Mit der neuen Behandlungsform AirFlow handy Perio geht es dem Biofilm an die Substanz. Die Lösung hierfür liegt im Detail: Das auf der Original Methode Air-Flow beruhende Perio-Flow-Spray-

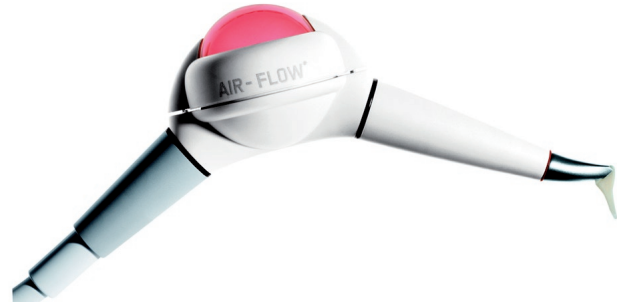

Abb. 9 Das neue Perio-Sprayhandstück ist mit der Perio-Flow-Einmal-Düse gut für das subgingivale Biofilmmanagement geeignet.

handstück hat eine speziell designte biokompatible Einweg-Düse. Mit dieser gelingt es, den kompletten Biofilm subgingival selbst aus den tiefsten parodontalen Taschen zu entfernen. Die einzigartige und patentierte Kombination bietet größtmögliche Effektivität mit höherem Patientenkomfort gegenüber herkömmlichen Küretten. Die Düse arbeitet mit sanfter, schmerzfreier biokinetischer Energie. Gemeinsam mit dem be- sonders feinen $25 \mu \mathrm{m}$, glycin-basierten, nicht abrasiven Perio-Pulver lässt sich zudem die immer häufiger auftretende Periimplantitis bei Implantatpatienten wirkungsvoll behandeln. Das Pulver trägt den Biofilm ab, ohne die Zahnsubstanz anzugreifen.

Die schnell konnektierbare Einweg-Düse reicht für die Behandlung von bis zu 15 Taschen. Die Düsen sind biokompatibel, besonders flexibel und biegsam. So erlauben sie den Zutritt zu allen Taschenbereichen. Der sanfte Perio-Strahl schont weiches, empfindliches Gewebe. 5 s reichen aus, um den Biofilm zu 100\% aus den meisten Taschen zu entfernen. Die Düsen sind für den Einmal-Gebrauch konzipiert und werden nach der Behandlung einfach entsorgt.

Dieser Beitrag ist entstanden mit freundlicher Unterstützung der EMS Electro Medical Systems GmbH, München. 